Vegueta. Anuario de la Facultad de Geografía e Historia

22 (1), 2022, 239-262

eISSN: 2341-1112

https://doi.org/10.51349/veg.2022.1.13

\title{
Serapis y los emperadores romanos a través de la numismática
}

\section{Sarapis and the Roman Emperors in the Light of Numismatics}

\author{
Verónica Reyes Barrios* \\ Universidad de Las Palmas de Gran Canaria \\ https:// orcid.org/0000-0002-7840-2929 \\ veronicareyesbarrios@gmail.com \\ Rosa María Sierra del Molino \\ Universidad de Las Palmas de Gran Canaria \\ Departamento de Ciencias Históricas \\ https:/ / orcid.org/0000-0002-5254-5227 \\ rosamaria.sierra@ulpgc.es
}

Recibido: 05/10/2021; Revisado: 09/11/2021; Aceptado: 29/12/2021

\section{Resumen}

Los materiales arqueológicos nos muestran la presencia del dios Serapis en todo el Mediterráneo; siendo considerable el número existente de objetos epigráficos, artísticos y numismáticos. Esta situación es consecuencia de la difusión, en el Mare Nostrum, de los cultos egipcios. En este artículo se estudiará la figura del dios y su relación con los emperadores romanos a través de las acuñaciones de monedas.

Palabras clave: Cultos mistéricos, Numismática, Religión egipcia, Religión romana.

\begin{abstract}
Archaeological materials show the existence of the god Sarapis throughout the Mediterranean, where a considerable number of epigraphic, artistic and numismatic objects remain. The presence of Sarapis in the Mare Nostrum is the result of the spread of Egyptian cults. This paper looks at Sarapis and his relationship with different Roman emperors, by way of the coins these latter had minted.
\end{abstract}

Keywords: Mystery Cults, Numismatics, Egyptian religion, Roman religion.

*Autora de correspondencia / Corresponding author.

Copyright: (C) 2022 ULPGC. Este es un artículo de acceso abierto distribuido bajo los términos de la licencia Creative Commons Atribución-NoComercial-SinDerivar (by-nc-nd) Spain 3.0. 


\section{INTRODUCCIÓN}

Alejandro Magno, entre los años 332-331 a.C., conquistó Egipto donde fundó Alejandría. Tras su muerte en Babilonia, en el año 323 a.C., comenzaron los problemas entre sus generales, los denominados diádocos. Estos se disputaron la dominación del extenso imperio que había creado el macedonio. Ptolomeo I Sóter gobernó Egipto (305-285 a.C.), fundó la dinastía de los Ptolomeos o Lágidas e hizo trasladar la capital de Menfis a Alejandría. El nuevo gobernante tuvo que legitimar su poder; por ello, creó a una nueva divinidad que recibió el nombre de Serapis.

La nueva capital de Egipto, Alejandría, necesitaba a un dios híbrido, es decir, que poseyera elementos tanto de la tradición egipcia, como de la griega para que fuera aceptado por ambas poblaciones, así como para unir a ambas culturas. Una parte de la historiografía (Alvar, 2001: 61-62; ARROYO, 1998:8-9) considera como posibles «padres teológicos» de Serapis, al sacerdote egipcio Manetón de Sebennitos y al sacerdote griego Timoteo. En este caso, el sacerdote egipcio contribuyó a la transformación del dios funerario Osiris y se apoyó en Timoteo, quien conocía bien la religión griega y los misterios eleusinos. La intencionalidad, como veníamos comentando, era helenizar a un dios egipcio.

Otros investigadores (WeLLES, 1962), afirman que no existen fuentes que adjudiquen directamente a ambos sacerdotes la creación del culto del dios. Mientras que, otros autores (ALVAR, 2001:62) prefieren dar importancia al hecho de que participaran conjuntamente dos religiosos de culturas distintas. En cualquier caso, Serapis es el resultado de una fusión entre dioses griegos y egipcios. Aunque en esencia, la deidad se fundamenta en el dios funerario nilótico Osiris (TERMIS, 2020:16-18). También está relacionado con el buey sagrado Apis (Termis, 2020:1819) y con el Agathos Daemon, la serpiente que protegió las casas y que murió por los trabajos realizados al fundar Alejandría. De ahí, que aparezcan representaciones de serpientes sagradas con cabeza de Serapis.

Respecto a los dioses griegos, Serapis, está relacionado con Hades, Zeus, Helios (Helioserapis), Dioniso, Asklepio y Poseidón. Del dios Hades tomó parte de su representación física -como es la presencia del Cancerbero en algunas esculturas- (Termis, 2020:19-20), de Zeus su aspecto (VeYMiers, 2009: 201-202), el atributo del águila y relación con el cosmos -lo mismo ocurrió con Amón-; con Helios se le relacionó por ser dios del sol (TuRCAN, 2001:120); con Asklepio queda asociado en su faceta de dios sanador (VEYMIERS, 2009: 153-155), mientras que se asimila a Poseidón como dios del mar y de los navegantes (BRICAULT, 2006: 155-170; VeYMIERS, 2009:53-54); finalmente, con Dioniso (TERMIS, 2020:21) se le vinculó por su relación con los cultos eleusinos. Además, al propio Osiris las fuentes griegas, a veces, lo denominan Dioniso: «[...] los griegos creen que Osiris es el mismo dios que Dioniso» (Plutarco, De Isis et Osiride, 13, 356). Los egipcios hicieron alusión al culto de la divinidad como Oserapis, hasta que los griegos helenizaron el nombre en Sarapis (TURCAN, 2001: 82).

El nuevo dios no quedó relegado en exclusividad al ámbito egipcio, sino que conquistó, junto a su esposa/hermana Isis, todo el Mediterráneo en mayor o menor medida. Dicha conquista se produjo principalmente gracias a los intereses de los Ptolomeos en el Egeo (MALAISE, 1972:37). Son muchos los vestigios arqueológicos existentes, tanto de Serapis como de Osiris, fuera de Egipto. Entre ellos encontramos epígrafes, monedas, esculturas, ushebtis, lamparillas, anillos, 
templos... Sin embargo, tras realizar una valoración cronológica, geográfica y arqueológica de la documentación existente, sobre el culto a ambas divinidades, hemos delimitado nuestro estudio a la presencia del dios Serapis en el marco del Imperio Romano usando como ejemplo las monedas que circularon a partir de la etapa imperial.

En este sentido hay que recordar la importancia de éstas, en la Antigüedad, debido a que fueron empleadas como un instrumento de difusión política y religiosa a través del uso de la iconología. En el caso de nuestro estudio nos encontramos con ejemplos de dracmas, tetradracmas, diobolos, áureos y, tras la crisis del imperio, aleaciones. Veremos cómo éstas circularon tanto en la parte occidental como en la oriental del imperio. ${ }^{1}$

En primer lugar, intentaremos explicar cómo llegó Serapis desde Egipto hasta Roma y cómo su culto pasó de estar prohibido a ser practicado hasta por los propios emperadores, ejemplificando la evolución con vestigios numismáticos. En segundo lugar, se estudiará y se clasificará la tipología de las monedas del dios. Y, finalmente, a partir de la información que nos ofrece la numismática y las fuentes secundarias, intentaremos examinar la adaptación de la imaginería de Serapis a las tendencias propagandistas religiosas de algunos emperadores, con el objetivo de transmitir mensajes ideológicos que repercuten en el beneficio político de su reinado.

\section{SERAPIS EN ROMA}

\subsection{Introducción del culto isíaco}

Hemos visto que Serapis nace como dios sincrético, pero ¿Cómo entró esta deidad a Roma? Algunos autores (SFAmENI, 2000:35-62) sostienen que el culto llegó al Imperio a través de Sicilia, debido a la importancia del lugar como ruta comercial. Esta hipótesis se apoya en la existencia de fuentes numismáticas en dicho lugar desde el siglo III a.C. Sin embargo, la mayoría de las teorías consideran que la introducción del culto en el Mediterráneo fue consecuencia, como mencionábamos, de los Ptolomeos (Malaise, 1972:37). En este sentido, resultan interesantes los datos que nos proporciona CuMONT (1987:73); según el cual los cultos egipcios fueron aceptados en todas las zonas geográficas donde los Lágidas tenían autoridad y reconocimiento.

Sin embargo, no toda la responsabilidad recae sobre la dinastía Ptolemaica. La actividad comercial fue un elemento importante, así como el comercio esclavista. Hay que recordar que el puerto de Alejandría fue un relevante emporion donde transitaban mercaderes y navegantes que se vieron influenciados por la cultura existente. A su vez, la isla de Delos también fue un prestigioso puerto comercial durante el siglo II a.C. En él se reunían comerciantes romanos, los cuales quedaron expuestos a la cultura griega $\mathrm{y}$, por lo tanto, a los cultos egipcios que se fueron

1 Existen excepciones como las emisiones realizadas por Gordiano III y Filipo II con el busto de Serapis enfrentado, tipología que solo fue emitidas a nivel local en la zona oriental del Imperio; un sacrificio realizado por Cómodo a Serapis emitidas solo en Alejandría y Roma o una moneda emitida por Caracalla en relación con el templo que le dedicó, a la deidad, en el Quirinal y la cual fue acuñada en Roma. 
introduciendo en Sicilia, Campania e Italia (MalaISE, 1972:45; DunAND, 1980:73-74). Por su parte, para los navegantes, Serapis se convirtió en una divinidad protectora de su oficio. De hecho, el sofista Elio Arístides (Oratio, 45) alude a la invocación de Serapis por parte de los marineros ante los peligros de una tormenta. Después de que el culto isíaco se estableciera en el sur de Italia, no tardó en llegar a Roma, entre los siglos II-I a.C. (BuREL, 1911; Le Corsu, 1977; WITT, 1971), siendo atractivo para los sectores sociales menos favorecidos. Desde Roma se expandió hacia las provincias (MALAISE, 1972:123).

En el período de Sila (82-79 a.C.) se fundaron collegia de pastophoros, es decir, de sacerdotes de la diosa Isis. Pero, el culto a Isis y Serapis no fue recibido, ni aceptado, de igual modo por los distintos gobernadores romanos. Tertuliano (APOL. VI, 8) hace referencia a las acciones, en contra de los cultos a los dioses nilóticos, llevadas a cabo por los cónsules Aulo Gabinio (58 a.C.) y Lucio Calpurnio Pisón (58 a.C.). Gabinio decretó la prohibición de la construcción de altares a estas divinidades. Además, tanto Gabinio como Pisón, pretendían desterrar a las divinidades para detener la expansión de una superstitio (SIERRA y CAMPOS, 2010:63). Más tarde, estos grupos se vieron favorecidos por el enfrentamiento político entre el Senado y Publio Clodio y sus seguidores, quienes reclutaron a esclavos y libertos contra la alta institución romana (TuRCAN, 2001:91). Resulta llamativa la actitud que tuvieron los devotos isíacos ante la demolición en el año 58 a.C., de los altares construidos en el Capitolio. Los fieles interrumpieron en un sacrificio oficial para recriminar a Gabinio su actuación (TerTULIANO, Ad. Nat. I, 10.18; Apol. vI, 8). En el 54 a.C. se aprobó un decreto senatorial por el cual se mandó destruir los templos que los fieles habían construido sin autorización, para rendir culto a los dioses egipcios. Los operarios se negaron y fue el propio cónsul, Lucio Emilio Paulo Macedónico quien golpeó la puerta del templo:

El cónsul Lucio Emilio Paulo, habiendo decretado el Senado que debían ser demolidos los santuarios de Isis y Serapis, al ver que ninguno de los obreros ni tan siquiera osaba acercarse a dichos templos, se quitó la toga pretexta, tomó un hacha y hendió las puertas de los mismos (VALERIO MáxImo, Hechos y Dichos Memorables, III.4).

No obstante, desde el año 59 a.C. los isiaci se habían agrupado en collegia, hecho que permitió el ejercicio de una presión constante para que los templos fueran construidos de nuevo. Un tiempo después, durante el mandato de Julio César, debido a su vinculación con la reina egipcia Cleopatra VII, se produce una aceptación temporal de los dioses nilóticos; de hecho, los astrónomos al reformar el calendario romano, denominado ahora calendario juliano (46 a.C.), quedaron incluidas las fiestas isíacas.

\subsection{Serapis y los emperadores romanos. El ejemplo numismático²}

A la muerte de César, el gobierno de Augusto (27 a.C.-14 d.C.) volvió a prohibir los cultos egipcios. El motivo se hallaba en el enfrentamiento contra Marco Antonio y Cleopatra VII. Mientras que el general romano se había mostrado como

2 Las siglas que se emplean son las siguientes: SNRIS= Sylloge Nummorum Religionis Isiacae et Sarapiacae; $R P C=$ Roman Provincial Coinage; $R I C=$ Roman Imperial Coinage. 
la reencarnación de Osiris, la reina egipcia, por su parte, se hizo llamar la 'Nueva Isis'. El triunfo de Octavio en la Batalla de Actium (31 a.C.) supuso una política de represión a dichos cultos, pues las deidades nilóticas no eran ni más ni menos que los dioses de los enemigos. Una vez que el vencedor volvió a Roma, vio con malos ojos que parte del ejército, que había luchado en Egipto, hubiese sido atraído por las divinidades nilóticas (BOHEE, 2000:129-132). De esta forma trató de difundir la cultura romana más tradicional (TAKÁCS, 1995:56) y prohibió la presencia de los cultos alejandrinos en el pomerium en el año 28 a.C.: «En lo que se refiere a los asuntos religiosos, [Augusto] prohibió que los rituales egipcios fueran celebrados dentro de los límites de la ciudad, pero veló por el mantenimiento de los templos romanos» (MONTERO, 2006:45). Lo paradójico es que, pese a tal persecución, la casa en el Palatino de la esposa de Augusto, Livia, tenía una decoración con motivos egipcios. Además, se encontraron "planchas de terracota con Isis entre dos esfinges en el templo de Apolo Palatino que estaba colindante a la residencia de Augusto» (TurCAN, 2001:92-93).

El general Agripa, en el año 21 a.C., extendió la prohibición más lejos: «hasta un radio de mil pasos» (CumONT, 1987:76) «[...] y en particular [Agripa] redujo la celebración de los ritos egipcios que invadían de nuevo la ciudad; prohibió celebrarlos a todos, incluso a los suburbios, en un radio de siete estadios y medio» (MonTERo, 2006:46). Los dioses también fueron perseguidos por el sucesor de Augusto, Tiberio (14-37 d.C.), ya que los cultos isíacos fueron acusados de corromper la moral de la mujer y pervertirla (SIERRA, 2006:65-66). En este sentido, Flavio Josefo (Ant. Jud. 18,72.) hace referencia a la historia de Paulina (Martín, 1994:135-144), mujer de un senador y devota isíaca, que rechaza en varias ocasiones al caballero Decio Mundo. Al conocer este de su vinculación con la diosa egipcia articula una estratagema para pasar la noche con ella, en el templo, reemplazando al dios Anubis. Respecto a este hecho, SUETONIO (Tib. 36) explica lo siguiente:

[Tiberio] Atajó los cultos procedentes del extranjero, especialmente los ritos egipcios y judaicos, obligando a todos los que practicaban esta religión a quemar las vestiduras y objetos de culto [...] desterró de Roma a los restantes judíos, así como a los seguidores de tipos análogo, conminándoles, si no obedecían, con la esclavitud para el resto de su vida.

La recuperación de los cultos isíacos fue cuestión de tiempo pues, a la muerte de Tiberio (37 d.C.), con Calígula (37-41 d.C.), se restableció su apoyo. Este emperador deseaba que hubiera espacio para las personas y los dioses de los nuevos territorios. También mandó construir un templo a Isis en el Campo de Marte. Este fue finalizado por Domiciano (81-96 d.C.) y se convirtió en un destacado monumento de Roma. Fue uno de los centros más importantes en las actividades religiosas de la urbe, sin embargo, no quedan restos, excepto el trazado de las calles. Bajo el mandato de Claudio (41-54 d.C.) (Figura 1) se registra la presencia del busto de la divinidad por primera vez, tras Ptolomeo IV, en la numismática alejandrina (MALAISE, 1972:385-395; BRICAULT, 2017:225) (MILNE=Alejandría 87; RPC I=Alejandría 5136; SNRIS=Alejandría 9, p. 240). Sin embargo, parece que el emperador se mostró más partidario de los cultos frigios (Bricault, 2008:240; Malaise, 1972:385). 

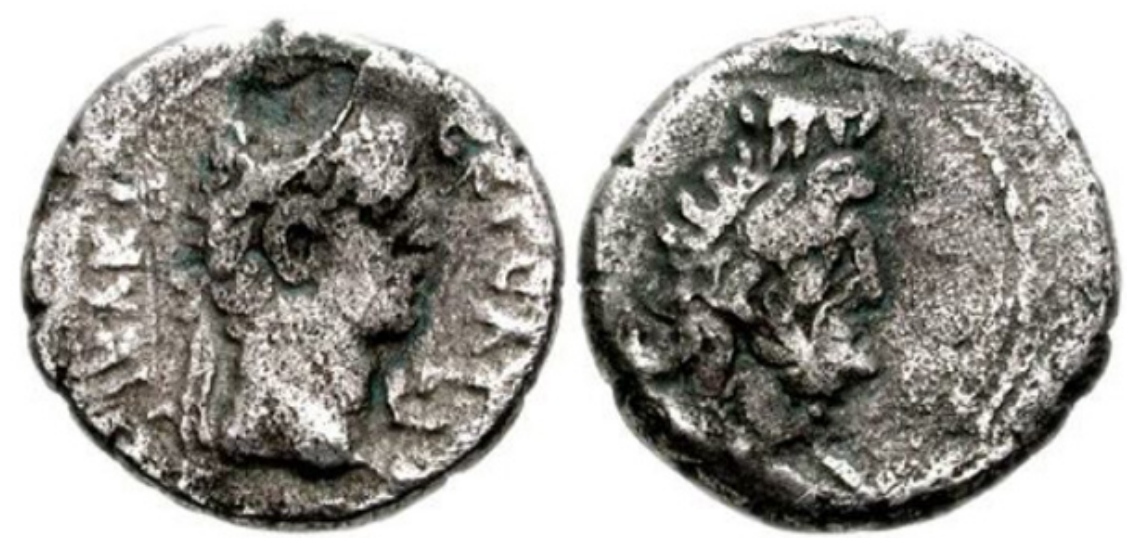

Figura 1. Busto de Claudio (anverso) y de Serapis (reverso)

Dracma, año 42/43 d.C., Alejandría, 15mm, 2.52 g. RCV I=Alejandría1871=Milne $87 \mathrm{a}=$ RPC 5136

https:/ / www.wildwinds.com/coins/sear5/s1871.html\#milne_087a

Vespasiano (Figura 2), el fundador de la dinastía Flavia (69-96 d.C.) (CARRADICE, 2012:375-389), visitó a Serapis en su santuario de Alejandría para ser legitimado por la propia divinidad -provenía de una familia de ordo ecuestre que alcanzó el rango senatorial (GASPARINI, 2009: 348)-. Después impulsó estos cultos convirtiéndose en un «hombre divino». Cuando fue proclamado emperador por el ejército de Oriente, Serapis fue el vínculo sobrenatural a la legitimación del acto. «El elegido de Serapis» acuñó monedas en Alejandría; entre ellas con el busto de Serapis en el reverso (RPC I= Alejandría 2433; SNRIS=Alejandría 33, p. 242), y, además, incluyó al dios híbrido entronizado (SNRIS=Alejandría 31, p. 242) o junto al Cancerbero (SNRIS=Alejandría 29, 30 p. 242). En estas últimas destaca la leyenda del reverso: ZEY $\Sigma$ AAPAПI $\Sigma$ (= Zeus Serapis) (VEYMIERS, 2009: 201202). Fuera de Roma y Alejandría, en Iconio, ${ }^{3}$ se registran monedas con el busto de Vespasiano en el anverso y Serapis entronizado en el reverso (SNRIS=Iconio 2, p. 242).

3 Ciudad de la provincia de Galatia, actual Konya (Turquía). 

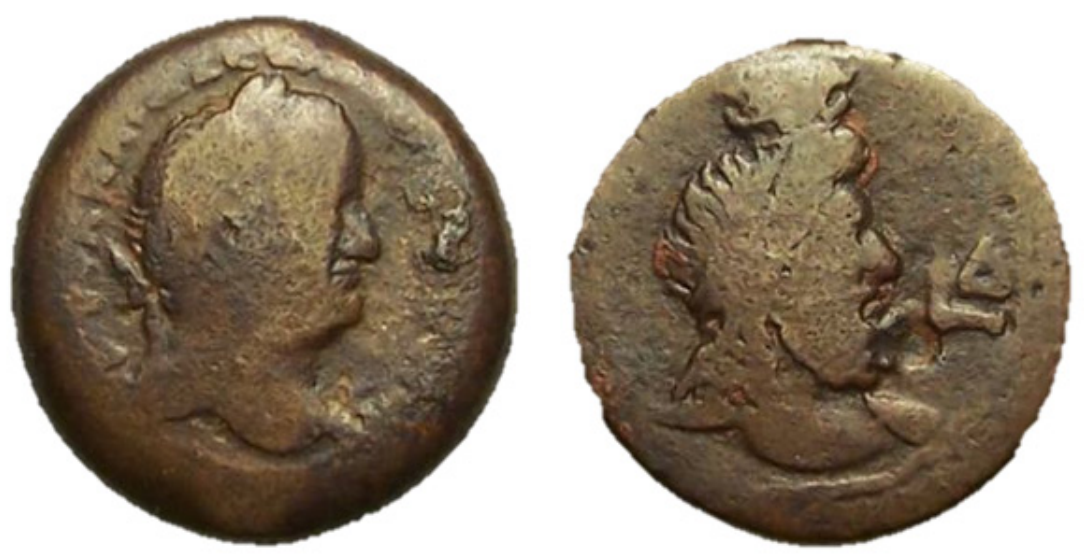

Figura 2. Busto de Vespasiano (anverso) y de Serapis (reverso)

AE Diobol, año 71/72 d.C., Alejandría, 25mm, $8.91 \mathrm{~g}$. $R P C_{\mathrm{I}}=$ Alejandría 2433

https://www.wildwinds.com/coins/ric/vespasian/RPC_2433.jpg

Los hijos de Vespasiano, los emperadores Tito (79-81 a.C.) (Figura 3) y Domiciano (81-96 a.C.) (Figura 4), también emitieron monedas con la figura de la deidad alejandrina. Algunos ejemplos de ello son las monedas de Tito en las que aparece el busto de Serapis (MilnE=Alejandría 456), Serapis en un kline en el reverso $\left(S N R I S=S_{i n o p e}^{4} 2\right.$, p. 109, 242) o las emisiones de Domiciano con el busto del dios a la derecha (MiLnE=Alejandría 466; RPC I= Alejandría 2505). La dinastía Flavia protegió a Isis restaurando sus santuarios (TAKÁCS, 1995:87).

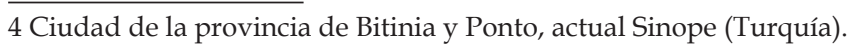



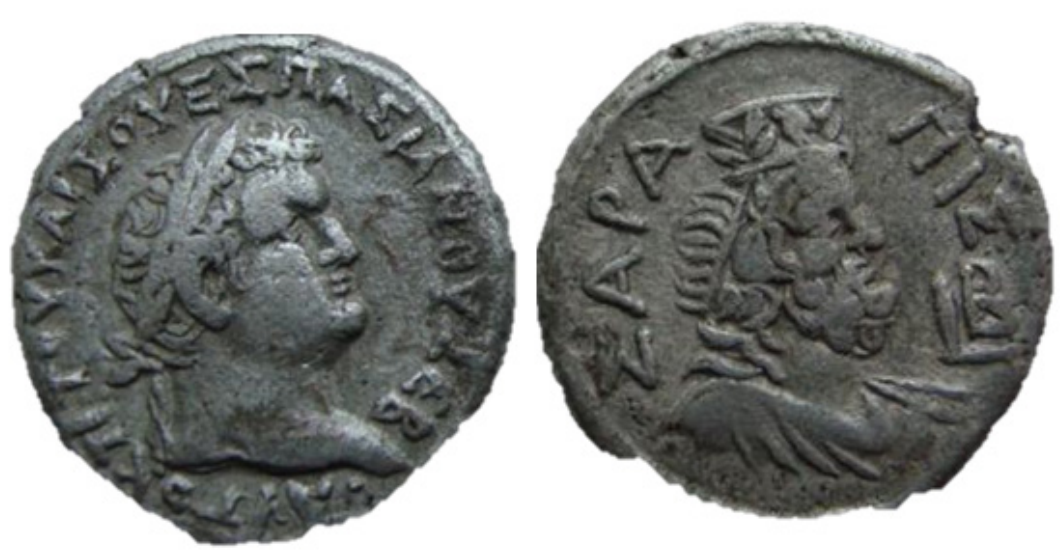

Figura 3. Busto de Tito (anverso) y de Serapis (reverso) Tetradracma, año 79-80 d.C., Alejandría, 25.4 mm, 12.254 g. MiLNE=Alejandría 2655456 https://www.wildwinds.com/coins/sear5/s2557.html
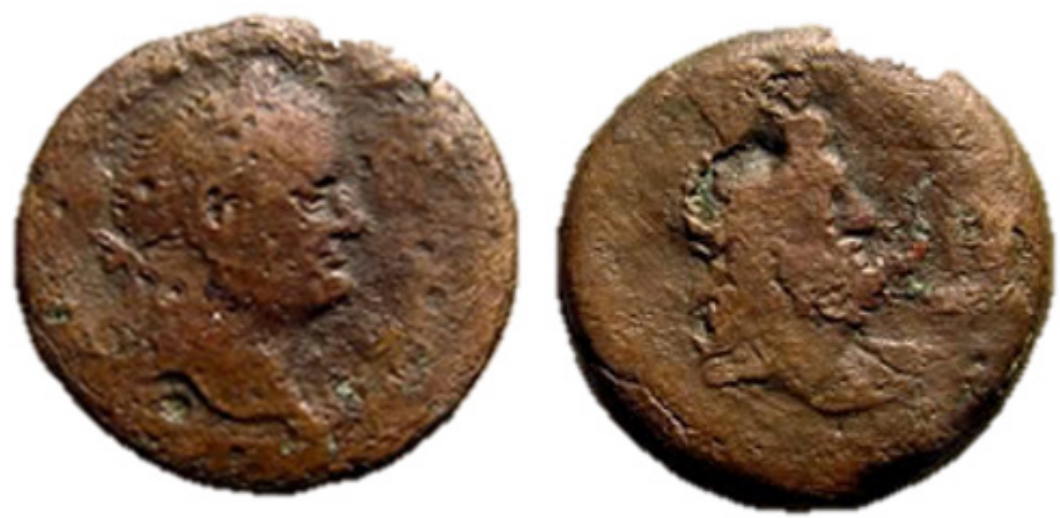

Figura 4. Busto de Domiciano (anverso) y de Serapis (reverso) Diobol, año 82-83 d.C., Alejandría, $4.49 \mathrm{~g}$. MiLNE=Alejandría 2655466

https://www.wildwinds.com/coins/ric/domitian/milne_466.jpg

Con la dinastía Antonina (96-192 d.C.) se registran cuarenta y dos Serapeos en Egipto (KRILL, 1978:29-32). Pero no todos los emperadores de la dinastía se mostraron especialmente seguidores de la familia isíaca; aunque no por ello dejaron de incluir entre sus emisiones a los dioses del Nilo (BAKHOUM, 1999:187). Son los casos de Nerva (96-98 d.C.), Trajano (98-117 d.C.), Antonino (138-161) y 
Marco Aurelio (161-180 d.C.) (MAlaise, 1972:418-436; BRICAUlt, 2008:242).

Adriano (117-138 d.C.) (Figura 5) mostró respeto por los cultos de origen egipcio y una inclinación especial hacia estos; un ejemplo de ello, lo hallamos en la Villa Adriana que contaba con una variada decoración de esculturas egipcias. En la propia villa, en el Antinoeion -dedicado al favorito de Adriano, Antínoo, quien fue asimilado a Osiris tras su muerte (REGGIANI, 2006:89)-, aparece la tríada de Isis, Serapis y Harpócrates. Adriano acuñó monedas de diversas tipologías; Serapis con otras divinidades (MiLne=Alejandría 840 var) o el dios entronizado (MiLNE=Alejandría 892 et 1255). Fue el primer emperador en reflejar a Isis y Serapis juntos en el mismo lado de una moneda (SNRIS=Roma 13 a, p.191). Posteriormente lo harán Cómodo (180-192 d.C.) y en el siglo III lo encontramos en las monedas emitidas por Claudio II (268-270 d.C.).
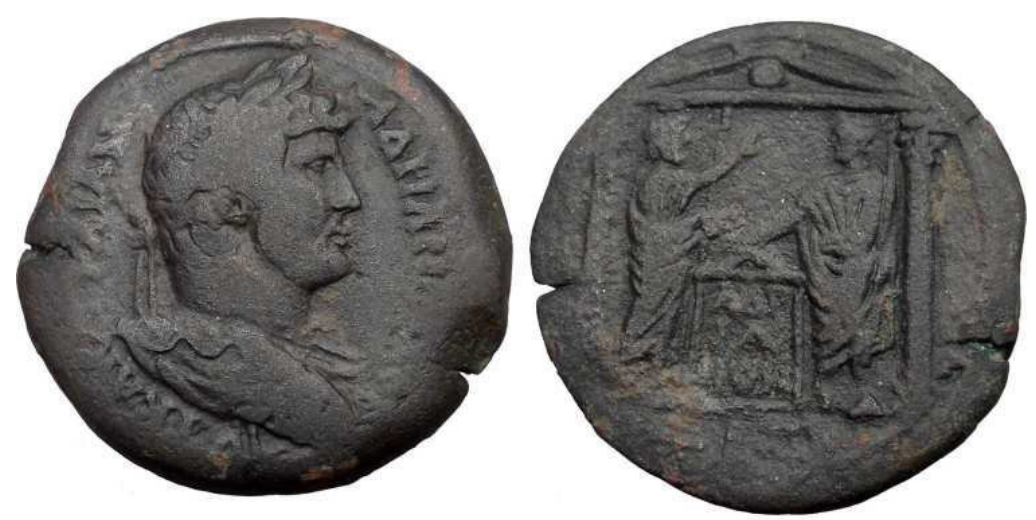

Figura 5. Busto de Adriano (anverso) y Serapis entronizado (reverso)

Dracma, año 117 d.C., Alejandría MiLNE=Alejandría 26551380

https://www.wildwinds.com/coins/ric/hadrian/Milne_1380.jpg

El número de talleres de emisiones monetarios con modelos isíacos aumentaron a partir de Antonino (138-161 d.C.) y Marco Aurelio (161-180 d.C.). Este hecho no está asociado con la predilección hacia este culto por parte de estos emperadores. Sin embargo, las emisiones fueron realizadas en nombre de la esposa de Marco Aurelio, Faustina la Menor, quien favoreció a la diosa Isis. En una de las monedas aparece Isis con un pavo real y un león, animal íntimamente asociado con Cibeles; quien contaba con el apoyo de Antonino y Marco Aurelio (BRICAULT, 2008:192).

A diferencia de su padre, Cómodo (180-192 d.C.) adoptó la costumbre egipcia de afeitarse la cabeza y apoyó a los dioses nilóticos como queda reflejado en las estatuas (WITT, 1997:70-71). Entre los años 180-190 d.C., la población romana se vio afectada por hambrunas (SILVER, 2012:199-225). Durante esta etapa Cómodo (Figura 6) llevó a cabo sacrificios tanto en Egipto (MiLnE=Alejandría 2653 et 2655) como en Roma. Las hambrunas finalizaron gracias a la llegada de barcos cargados de trigo procedentes de Alejandría. Posteriormente estos sacrificios quedaron reflejados en una serie de monedas emitidas en el año 190 d.C. en Roma 
(SNRIS=Roma M5a-b, p.192); en cuyo anverso aparece el busto del emperador con la leyenda IMP COMMODVS AVG PIVS FELIX y en el reverso hallamos una escena. En ella, el emperador se encuentra en el faro del puerto de Ostia ofreciendo el sacrificio de un toro. Hacia ellos van cinco barcos; dos galeras y tres barcos más pequeños con remos. En el barco mayor aparece Serapis sentado en la popa. En la leyenda figura VOTIS FELICIBVS. Algunos autores lo relacionan con el Vota publica del Año Nuevo (Royo, 2017:183-186) o con el Navigium Isidis celebrado el 5 de marzo (ALFöDI, 1965-66:53-87). Otros autores, defienden una mayor relación con las Felicitas de la propaganda imperial (BEAUJEu, 1955: 96-192). En ese mismo año, Cómodo, se declaró bajo la protección de ambos dioses. Por ello, entre los años 191 y 192 d.C., Serapis aparece en las monedas como CONSERV(ator) $A V G$ (vsti) (=Conservador, salvador de Augusto) (SNRIS=Roma 19, p. 193).
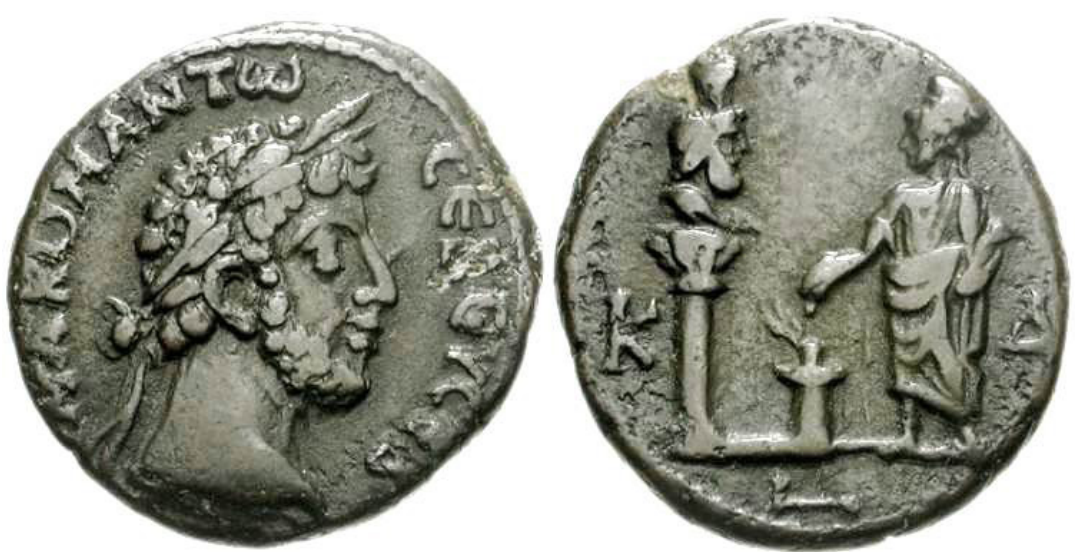

Figura 6. Busto de Cómodo (anverso) realizando un sacrificio sobre un altar a Serapis (reverso)

Tetradracma, año 183-184 d.C., Alejandría, 24 mm, $16.62 \mathrm{~g}$. MiLNE=Alejandría 2655

https://www.wildwinds.com/coins/ric/commodus/Milne_2655_2.jpg

En la dinastía de los Severos (193-235 d.C.), Caracalla (211-217 d.C.) (Figura 7) estuvo muy relacionado con el dios y lo vinculó con la salud. En el Serapeum de Alejandría era conocido de manera oficial bajo el nombre Philosarapis, es decir el «predilecto de Serapis». El emperador mantuvo una gran actividad numismática (JohNSTON, 1983:58-76) (RIC IV, I= Roma193 et 194; SNRIS=Serdica5 22, p. 42). En Roma, Caracalla, consagró un templo al dios en el Quirinal (SNRIS=Roma 24, p. 194). Mientras que en el anverso aparece el busto del emperador, en el reverso aparece el dios dentro del templo junto a la leyenda IOVI SOSPITATORI (= Júpiter protector). Además, en las termas aparece una inscripción en la que alude a la divinidad del siguiente modo: «Sólo [existe] Zeus- Sarapis-Helios, señor invencible del mundo» (TURCAN, 2001:96; VeYMers, 2009:204). Heliogábalo (218-222 d.C.) también se hizo representar con el dios (MiLnE=Alejandría 2780). Y, Severo Alejandro (222-235 d.C.) (Figura 8) (Milne=Alejandría 4356), además,

5 Ciudad de la provincia de Dacia, actual Sofía (Bulgaria). 
contribuyó al Iseum Campense con estatuas de Delos y otros monumentos que incluían jeroglíficos, al igual que se encargó de embellecer el Serapeo construido por Caracalla en el Quirinal (DuNAND, 1968:151-155).
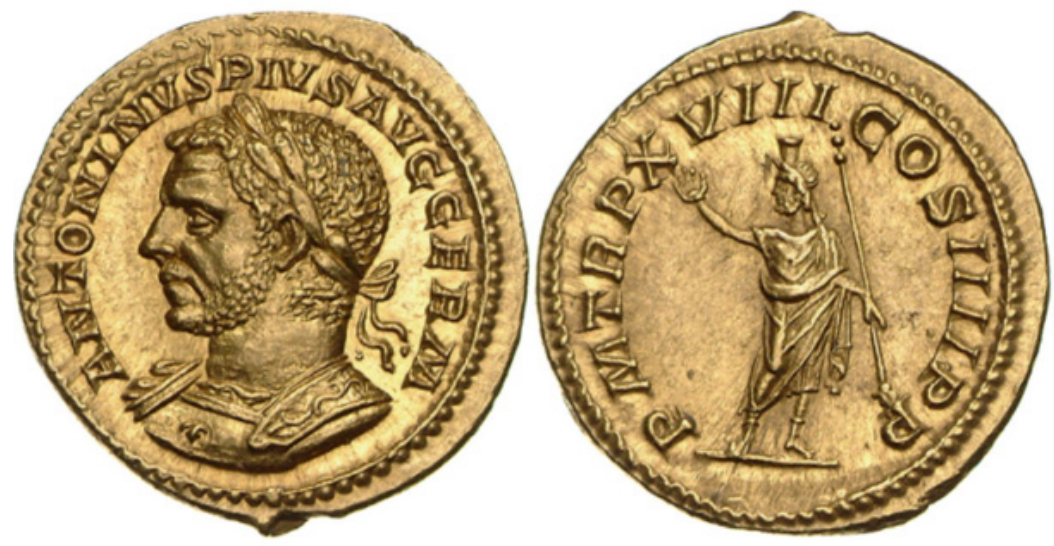

Figura 7. Busto de Caracalla (anverso) y Serapis de pie (reverso) Áureo, Roma, $20 \mathrm{~mm}, 6.54 \mathrm{~g}$.

(C) Münzkabinett der Staatlichen Museen zu Berlin - Preußischer Kulturbesitz, $\mathrm{n}^{\mathrm{o}}$ inv. 18204262
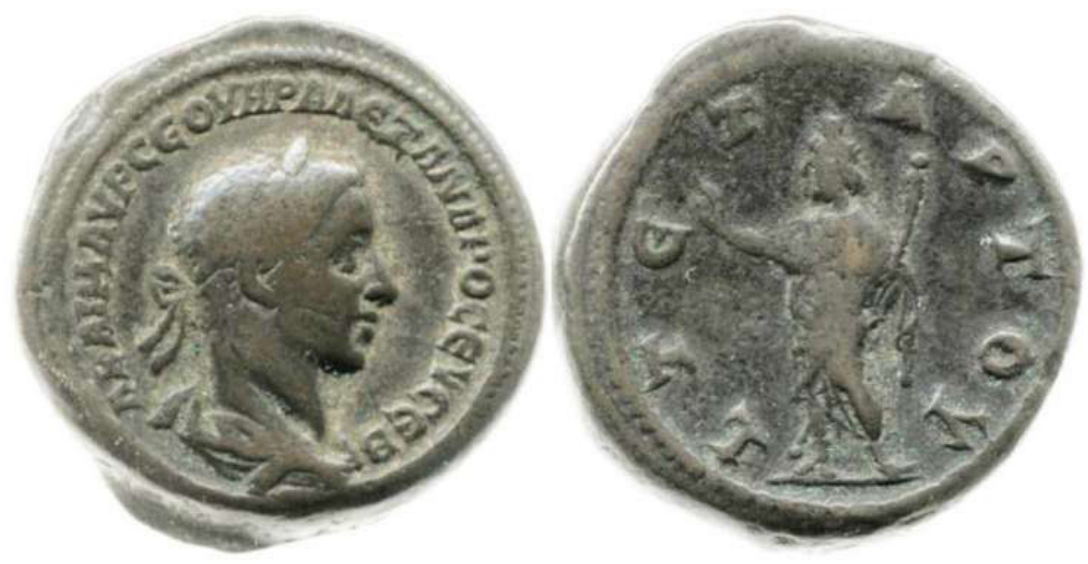

Figura 8. Busto de Severo Alejandro (anverso) y Serapis de pie (reverso) Tetradracma, Alejandría, año 224-225 d.C., 24 mm, $11.70 \mathrm{~g}$. DATTARI=Alejandría 4356

https://www.wildwinds.com/coins/ric/severus_alexander/Dattari_4356.jpg 
Es a comienzos del siglo III d.C. cuando el culto a Serapis e Isis alcanza su mayor apogeo. La importancia de las divinidades del ciclo isíaco en las monedas provinciales muestra cómo se habían integrado en los panteones locales. Hay que tener en cuenta que la producción de monedas provinciales orientales es importante durante este siglo por el menor número de emisiones de otro tipo, como fueron los sestercios, debido a la crisis monetaria iniciada con Caracalla. Las ciudades tuvieron que emitir monedas para complacer las necesidades locales (BRICAUlt, 2008:246). Así, fueron las cecas de las ciudades orientales del Imperio las que realizaron acuñaciones. Por lo que vieron cómo aumentó poco a poco su producción en la primera mitad del siglo i d.C.

A mediados del siglo III hallamos emisiones de los emperadores Gordiano III (238-244 d.C.) (Figura 9) (RIC IV-III=Antioquía 30 v; SNRIS=Alejandría 602c, p. 37) y Filipo II el Joven (247-249 d.C.) (Figura 10) (MousHMOv=Marcianópolis ${ }^{7}$ $858,859,859 v$; SNRIS=Marcianópolis 28, p. 45) en compañía del busto de Serapis. Son significativas las emisiones de Gordiano III emitidas en las ciudades de Tomis, ${ }^{8}$ Marcianópolis y Odessa $a^{9}$ bajo el contexto de las campañas realizadas por el emperador en Tracia y Mesia (CALOMINo, 2013:109).
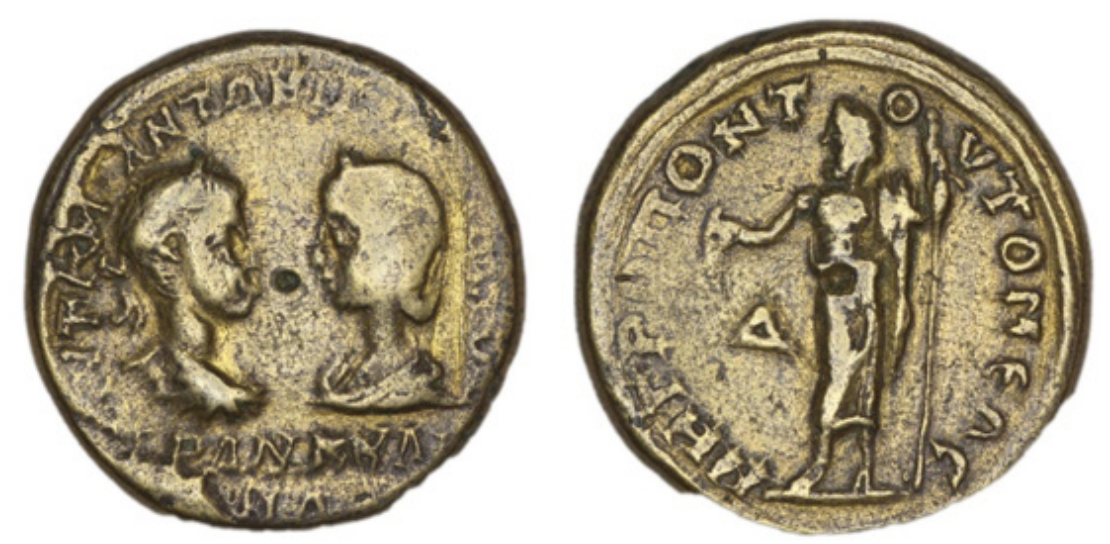

Figura 9. Busto de Gordiano III (anverso) y Serapis de pie (reverso) Aleación, Tomis, año 238-244 d.C., $11.55 \mathrm{~g}$.

(C) The Trustees of the British Museum, $\mathrm{n}^{\circ}$ inv. 1921,0213.55

6 Ciudad de la provincia de Siria, actual Antioquía (Turquía).

7 Ciudad de la provincia de Tracia/Mesia Inferior, actual Devnya (Bulgaria).

8 Ciudad de la provincia de Mesia Inferior, actual Constanza (Rumanía).

9 Ciudad de la provincia de Mesia inferior, actual Varna (Bulgaria). 

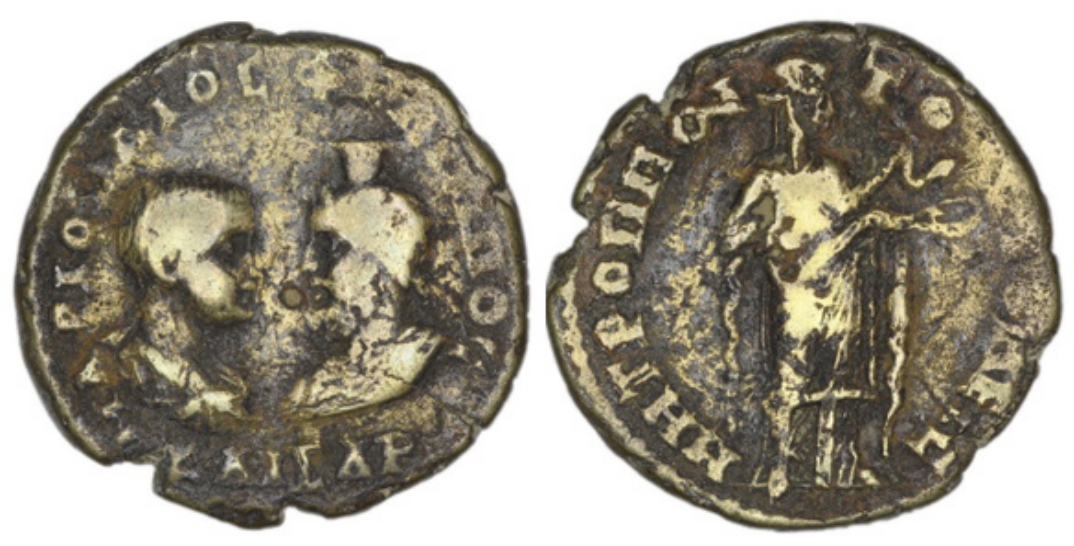

Figura 10. Bustos enfrentados de Filipo II el Joven y Serapis (anverso) Aleación, Tomis, año 244-249 d.C., $11.31 \mathrm{~g}$.

(C) The Trustees of the British Museum, $\mathrm{n}^{\circ}$ inv. 1898,1005.11

Galieno (253-268 d.C.) (MiLne=Alejandría 4028) y su familia mostraron gran interés por los cultos isíacos, ya que se registran 18 ciudades con monedas en las que aparecen los nombres de su esposa Cornelia Salonina y sus hijos Salonino, Mariniano y Valeriano II (SNRIS=Roma 41, p.197). En el año 11 del gobierno de Galieno, la ceca de Alejandría originó un nuevo tipo de reverso en la que aparece Serapis entre Ares (o el propio emperador identificado con la deidad) y Niké (SNRIS=Alejandría 659, p.197).

A finales de este siglo las monedas provinciales desaparecieron ya que se paralizaron las emisiones de las monedas orientales. Entre los años 308-313 d.C. hubo emisiones desde la ceca de Alejandría; Antioquía, Cícico, ${ }^{10}$ y Nicomedia ${ }^{11}$ acuñaron monedas con el Sol Invictus en el reverso y en la mano un busto de Serapis. Estas fueron acuñadas por Maximino Daya César (305-313 d.C.) (SNRIS=Alejandría 731-733, p. 45, 248; Heraclea ${ }^{12}$ 3, p. 248); Licinio (308-325 d.C.) y Constantino (306-337 d.C.) (SNRIS= Antioquía 10-16, p. 248; Nicomedia, 2830 p. 248). Maximino Daya César (305-313 d.C.) poseía el control de la ceca de Alejandría (BRICAULT, 2008:246), pero su caída marcó el fin de la presencia isíaca en el numerario. Sin embargo, las monedas de latón de Roma con la inscripción VOTA PVBLICA no desaparecieron hasta finales del siglo IV (Royo, 2017:186).

\subsection{Tipología numismática}

La aparición de Serapis en las acuñaciones del Mediterráneo es extensa. Existe una variada tipología de emisiones: el as (bronce), el áureo (oro), el

10 Ciudad de la provincia de Misia, actual Aidinjik (Turquía).

11 Ciudad de la provincia de Bitinia y Ponto, actual Izmit (Turquía).

12 Ciudad de la provincia de Tracia, actual Marmara Eregli (Turquía). Después del siglo Iv puede aparecer como Heraclea, Heraclea de Tracia o Heraclea Perinto. 
denario (plata), el sestercio (1/4 de denario) y el dupondio (equivalente a dos ases). La iconografía que refleja la figura del dios sincrético también es variada, pero intentaremos centrarnos solamente en aquellas que guarden algún tipo de relación con Roma y sus emperadores.

En primer lugar, podemos hablar de un gran grupo que se caracteriza por representar el busto o la cabeza del dios (VEYMIERS, 2009:23-33), siendo un tipo de efigie muy característica. La imagen puede ser frontal o lateral. Aunque Serapis aparece de frente en esculturas, joyas o lamparillas; no es la posición común que presenta en las monedas. Sin embargo, existen excepciones. Por ejemplo, hallamos monedas romanas donde aparece acuñado VOTA PVBLICA y la divinidad figura de frente portando el característico kalathos (ALFÖDI=Roma 207; VAGI= Roma 3371; SNRIS=Roma v100, p. 37).

Es más común la representación del busto de la divinidad vista de perfil. Según BRICAUlt (2008:37), el primer ejemplo de moneda en la que Serapis se muestra en esta posición, es decir, de perfil, es el tetradracma de Ptolomeo IV Filopátor, datada del año 217 a.C. (SNRIS=Alejandría 2, p. 43,84). En este tipo de monedas, Serapis se presenta como un hombre mayor; con cabello y barba rizada; manifestando un gran parecido físico a los dioses griegos Zeus, Hades y Asklepio. A veces lleva el kalathos (VEYMIERs, 2009:31), un tipo de corona con forma de cesta que se va ensanchando en la parte superior. Simboliza la fertilidad agraria y, por ello, aparece decorado con elementos naturales (hojas de palma, de trigo...). ${ }^{13}$ Esta tipología de tocado está atribuida a otras divinidades, como la diosa de la agricultura Deméter, a su vez vinculada a los Misterios Eleusinos, o a la deidad de la fortuna, Tyche. En las primeras representaciones de Serapis, el dios no portaba el kalathos, sino la corona egipcia atef, en alusión a su relación con Osiris, y el cuerno de carnero de Amón o el basileion. Puede que su uso se produjera a finales del siglo II-I a.C. (BRICAULT, 2017:216).

En algunos casos, el busto de Serapis aparece junto al de Isis (MousHMOV=Perinto ${ }^{14}$ 4398, SNRIS=Nicaea ${ }^{15}$ 9, p.42). Ambos están posicionados de lado; el dios en un primer plano, mientras que la diosa queda en un segundo lugar. Normalmente están girados hacia la derecha. Esta representación alude a los bustos de las parejas reales. No obstante, también pueden aparecer las divinidades una frente a otra. En algunos casos entre ambos dioses puede emerger un águila y/o Harpócrates (SNRIS=Alejandría 214, p.44). Lo interesante de este tipo iconográfico es que tiene su origen en las monedas romanas, como es el caso de los bustos enfrentados de Antonio y Octavia (BABELON, 1951:83). Sin embargo, este tipo de imágenes sólo figuran en Roma desde la segunda mitad del siglo I d.C. en lamparillas (BRICAUlT, 2008:43). Por el contrario, resulta curioso que este tipo de representaciones sí que aparece en Oriente $(S N R I S=$ Alejandría $257 \mathrm{~b}, \mathrm{p}$. 43; Nicomedia 20, p.44). No es fácil resolver los motivos que condujeron a esta situación. Quizá la trayectoria política de Marco Antonio, con respecto a Egipto, no sea un hecho que Roma desee recordar. ${ }^{16}$

13 Serapis es representado con este tipo de tocado en un 98\% de las monedas (BRICAULT, 2008:41). 14 Ciudad de la provincia de Heraclea de Tracia o Heraclea Perinto, actual Marmara Eregli (Turquía). 15 Ciudad de Bitinia, actual Iznik (Turquía).

16 El hecho de que Cleopatra fuera considerada la «Nueva Isis» y Marco Antonio, Osiris; podría haber sido suficiente para que la imagen de la diosa Nilótica en actitud cariñosa con el dios alejandrino, o incluso, ambas divinidades besándose, no fuera un icono idóneo para ser propagado en la propia ciudad de Roma. 
Por otro lado, Serapis puede aparecer frente al dios Helios, aunque es una moneda poco frecuente ya que solo se registra en Nicomedia (SNRIS=Nicomedia 22, p. 44) y en Alejandría (SNRIS=Alejandría 707, p. 44). Osiris estaba vinculado con el sol y como heredero de éste, a Serapis se le vinculó con Helios (Helioserapis) (Veymiers, 2009:191-200; PéreZ, 2020:248). Asimismo, la divinidad puede aparecer portando la corona radiada, simbología solar (VAGI=Roma 3370; SNRIS=Alejandría 40, p.20).

En otros casos, el busto del dios aparece frente al de un gobernante. La divinidad actúa como compañero del emperador (MALAISE, 1984:444). Ejemplos de ello son los emperadores Gordiano III (238-244 d.C.) (Moushmov= Dionysopolis ${ }^{17}$ 119; SNRIS=Alejandría 602c, p. 37) y Filipo II (247-249 d.C.) (MousHMOV=Tomis 2324; VARBANOV=Mesembria ${ }^{18}$ 4285; SNRIS=Marcianópolis 28, p. 45). Esta particular representación del príncipe enfrentado a la divinidad fue introducida por primera vez por Gordiano III en Odessa, ${ }^{19}$ Marcianópolis, Tomis, Dionysopolis y Mesembria. Las emisiones fueron realizadas en el contexto de la expedición de Mesia y Persia por parte de Gordiano III (CALOMINO, 2013: 113-114).

Filipo el Árabe, había sido prefecto del pretorio de Gordiano III. Una vez que este muere, el primero es nombrado emperador (244-249 d.C.) y su hijo, Filipo II, fue nombrado Augusto y co-emperador (247 d.C.). Pese a la corta vida de Filipo II, quien fue asesinado con once años, hallamos, como mencionábamos, este mismo tipo de emisiones en los mismos lugares emitidos por Gordiano III, excepto Odessa. La vasta cantidad de esta tipología nos hace pensar que se puede tratar de un tipo de iconografía sucesoria. El dios ya había actuado así en origen, cuando Ptolomeo Soter I lo usó para legitimar su gobierno en Egipto. Además, no es de extrañar que Filipo el Árabe quisiera hacer propaganda sucesoria de su hijo y empleara una tipología emitida por su predecesor Gordiano III.

En segundo lugar, existe todo un repertorio iconográfico en el que el dios aparece de pie (VEYMIERS, 2009:81-91) (RIC IV, I =Roma 193-194; SNRIS= Alejandría 722 , p. 47). Este tipo es muy común; de hecho, en los Serapeos e Iseos las estatuas halladas son mayoritariamente imágenes en las que el dios aparece en esta posición, en comparación a Serapis entronizado (TRAN TAM TIN, 1983:21-22). En ellas, al dios se le representa vestido con un quitón griego y encima de este un himatión. A veces, el torso aparece desnudo. Sobre la cabeza porta el kalathos y en los pies lleva unas sandalias griegas. La postura de pie, de la divinidad, tiene su origen en el tipo de imagen que había en el Serapeum de Menfis, el cual gozó de gran popularidad y aceptación. Por lo tanto, es un tipo de representación habitual de época helenística (Stambaugh, 1972:21). Si el dios aparece solo, suele hacerlo de frente, aunque su cabeza quede virada hacia un lado. El cuerpo también se presenta girado, aunque en menor medida. Uno de sus brazos está levantado con la palma abierta -en modo de salvación, protección o salud (ad locutio)- y el otro, sostiene un largo cetro. En estos casos la divinidad aparece como un pantocrátor (Tran tam Tin, 1983:62-63; Veymiers, 2009:86).

Dentro de este gran grupo también hay ejemplos en los que se incluye a Isis

17 Ciudad de la antigua Moesia, actual puerto de Bachik (Bulgaria).

18 Ciudad de la provincia de Tracia, actual Nesebar (Bulgaria).

19 En esta región el Gran Dios Darzalas fue asimilado a Serapis, especialmente durante la Roma Imperial. Darzalas es representado como un hombre barbudo, con kalathos, cornucopia y una patera (CAlomino, 2013:111). 
$\left(S N R I S=H_{a d r i a n i a^{20}}\right.$ 5, p. 51). La diosa suele portar sus atributos característicos; es decir, un sistro y una sítula. Respecto al primero, podemos decir que es un instrumento musical muy usado por otras diosas egipcias como, por ejemplo, la diosa celeste Bat o la diosa gata Bastet. En cuanto a la sítula, es una vasija en el que la diosa portaba el agua mágica del Nilo. La vestimenta de la deidad está formada por el quitón y el himatión rematado; el conjunto, por el nudo isíaco.

En su condición de dios helenizado, Serapis, en algunas monedas emitidas por los Severos, es identificado con el dios griego de la medicina Asklepios (VEYMIERS, 2009:153-155), adaptado por los romanos bajo el nombre de Esculapio. Dicha identificación se debe a que, en estos casos, Serapis aparece con un bastón y una serpiente enrollada en este (SNRIS $=S$ tobi $^{21} 1-4$, p.51, 91).

Así mismo, una vez que Serapis fue aceptado en Roma, muchos emperadores no dudaron en vincularse a él y hacerse representar siendo coronados por el dios. Ejemplo de ello es el "predilecto de Serapis», Caracalla (211-217 d.C.) (RIC IV, I=Roma 208a; SNRIS=Nicaea 19, p. 51, 108; Nicomedia 10, p. 51, 52, 108; Ptolemais $^{22}$ 7, p. 51) o Alejandro Severo (222-235 d.C.) (Milne=Alejandría 2811; SNRIS=Perinto 15, p.51, 206; Ptolemais 11, p. 51). El propio Alejandro Severo emitió una moneda bastante excepcional, en la cual Serapis aparece subido en una cuadriga (VEYMIERS, 2009:86-87) (SNRIS=Aspendo ${ }^{23} 16.1$, p. 145). Este tipo, tan peculiar, de acuñaciones también fueron emitidas bajo el mandato de Adriano (117-138 d.C.) (SNRIS=Alejandría 207, p. 54) o Séptimo Severo (193-197 d.C.) (SNRIS=Germanicopolis ${ }^{24}$, p. 54,106).

El tercer grupo de monedas hace referencia a todas aquellas en las que Serapis aparece entronizado. La descripción está basada en la imagen que representa la escultura asociada al tallista griego Briaxis. Según la tradición, se encargó a este escultor la creación de la imagen de Serapis. Sin embargo, autores como Turcan consideran que, la obra, pudo ser inspiración de un autor homónimo (TURCAN, 2001:83). Por su parte, Malaise tacha de frágil considerar que Serapis entronizado reproduzca la estatua original del Serapeo de Alejandría de Briaxis (MALAISE, 1975:383-391). La imagen de Serapis entronizado (VEYMIERS, 2009:116-123) es propia de la estética griega; muy característica en representaciones de otros dioses como Zeus o Hades. Serapis aparece como un hombre adulto, con barba y cabello rizado; vestido con el quitón, llevando sandalias y portando el kalathos. Está sentado en un trono y mientras con una mano sostiene un cetro, con la otra, acaricia la cabeza del Cancerbero (MiLnE=1398). Como en los grupos anteriores, lo común es que el dios aparezca de perfil. Es una tipología muy utilizada hasta el siglo III d.C. (BRICAULT, 2008:54). Un ejemplo de ello, es una emisión en la que aparece Serapis entronizado dentro de un templo (VEYMIERS \& BRICAULT, 2018:127155) (SNRIS=Roma 11, p. 63). En este tipo de figuraciones Serapis lleva la misma vestimenta que cuando aparece de pie, es decir, un himatión y un quitón. En algunas monedas también puede aparecer con el torso desnudo. El trono en el que se sienta el dios sincrético presenta un respaldo alto, a diferencia del egipcio, que se caracteriza por ser más bajo. En ocasiones, puede aparecer un pequeño taburete donde la divinidad descansa sus pies. Su origen parece hallarse en el

20 Ciudad de la antigua Misia, actual Dursunbey (Turquía).

21 Ciudad de la provincia de Macedonia, actual Gradsko (Macedonia del Norte).

22 Ptolemaida (Tolmeta) en Cirenaica.

23 Ciudad de la provincia de Licia y Panfilia, actual Büyükbelkiz (Turquía).

24 Ciudad de la provincia de Bitinia y Ponto, actual Tahtali (Turquía). 
Zeus Olímpico de Fidias (VeYmiers, 2009:61). Por otro lado, en algunas emisiones datadas desde época de Trajano (98-117 d.C.) (SNRIS=Alejandría 65, p. 58) hasta Diocleciano (284-305 d.C.) (SNRIS=Alejandría 695, p. 58), se presenta con una o dos pequeñas Niké coronando a Serapis (VeYMIERS, 2009:123).

Un cuarto grupo que podemos hallar se caracteriza por la presencia de Serapis en un templo (Milne=2013). En la ciudad romana de Nicópolis de Istro, ${ }^{25}$ fundada por Trajano (101-106 d.C.), se registran ejemplos de la deidad en un santuario tetrástilo en las que aparece Caracalla (211-217 d.C.) (SNRIS=Marcianópolis 9a, p. 61), así como Gordiano III (238-244 d.C.) (SNRIS=Marcianópolis 26, p. 60). También aparecen ejemplos en otras ciudades como Develtos ${ }^{26}$ o Anchialos, ${ }^{27}$ donde hay testimonios de emisiones de monedas de esta tipología con Alejandro Severo (222235 d.C.) (SNRIS=Anchialos 5, p. 61) y Gordiano III (238-244 d.C.) (SNRIS=Develtos $11 \mathrm{ab}$, p. 62). En este modelo la deidad presenta su iconografía característica (túnica griega, kalathos y largo cetro). Cuando aparece entronizado suele ir acompañado del Cancerbero.

Por último, existen las particulares monedas en las que aparece Serapis a caballo; emisiones emitidas en la ciudad de Istros. ${ }^{28}$ Dichas transmisiones abarcan desde el reinado de Cómodo hasta el de Gordiano III (SNRIS=Istros 1-10, p.65). En ellas aparece un hombre con barba, kalathos, vestido con un abrigo largo y en caballo. Detrás de él hay un altar sobre el que descansa un águila. Desde el reinado de Séptimo Severo se representa un altar debajo de la pata levantada del caballo.

\section{CONCLUSIONES}

Tras analizar cómo los cultos isíacos entran en Roma, hemos podido comprobar el gran número existente de vestigios numismáticos relacionados con Serapis y los emperadores romanos. Esta considerable presencia indica la importancia y el favor del que gozaron dichos cultos durante la etapa imperial.

La cronología de las monedas en Roma, como hemos observado, abarca desde el siglo I d.C. hasta el Iv d.C.; es decir, desde la dinastía Julio-Claudia con Claudio (41-54 d.C.) hasta el final del paganismo en el siglo Iv d.C. Por lo tanto, Serapis no sólo llegó a formar parte de la religión oficial romana, sino que contó con el favor de muchos de los emperadores romanos. Sin embargo, hay que indicar que las emisiones en época imperial que hacen referencia a los cultos isíacos son discontinuas.

Así, tras el análisis realizado, podemos determinar que durante el Principado (27 a.C. -14 d.C.) y la dinastía Julio-Claudia (14-68 d.C.) fue cuando menos actividad numismática relacionada con los cultos isíacos existió; sobre todo, si recordamos la exclusión que sufrieron por parte de Augusto (27 a.C.-14 d.C.) y Tiberio (14-37 d.C.). No obstante, hay un apoyo explícito durante la dinastía

25 Provincia de Veliko Tarnovo, actualmente las ruinas se hallan en las inmediaciones de Nikyuo (Bulgaria).

26 Ciudad de la provincia de Tracia, la antigua ciudad estaba ubicada cerca de Debel (Bulgaria).

27 Ciudad de la provincia de Tracia, actual Pomorie (Bulgaria).

28 También denominada Histria. Ciudad de la provincia de Mesia Inferior, actualmente es un yacimiento arqueológico (Rumanía). 
Flavia iniciada con la figura de Vespasiano ${ }^{29}$ (69-79 d.C.) y continuada con sus sucesores Tito (79-81 a.C.) y Domiciano (81-96 a.C.), hecho que queda constatado en las representaciones monetarias donde Serapis figura con la tipología más característica: de busto, entronizado y en kline. Pero este respaldo a las divinidades nilóticas no tuvo siempre la misma intensidad; se constata hasta la llegada de los Severos que sólo de forma particular algunos emperadores de la dinastía Antonina quedaron vinculados a Serapis, como Adriano (117-138 d.C.) y Cómodo (180-192 d.C.).

Resulta elocuente, por tanto, que aunque los cultos isíacos ganaron el apoyo de varios emperadores, quienes más aparecen junto a Serapis son los pertenecientes a la dinastía Severa; especialmente, los emperadores Séptimo Severo (193-197 d.C.) $(S N R I S=$ Germaniopolis 4, p. 54,106); Caracalla (211-217 d.C. $)(R I C$ IV , I =Roma 193-194; SNRIS=Nicaea 19, p. 51, 108; Nicomedia 10, p. 51, 52, 108; Marcianópolis 9a, p. 61, Ptolemais 7, p. 51) y Alejandro Severo (222-235 d.C.) (Milne= Alejandría 2780 et 2811; SNRIS= Anchialos 5, p. 61, Aspendo 16.1, p. 145, Perinto 15, p.51, 206; Ptolemais 11, p. 51). Con Caracalla los cultos egipcios fueron introducidos dentro del pomerium (GARCía, 2001:177); de hecho, es el período de mayor registro de monedas isíacas, así como de talleres emisores; sirva como ejemplo especialmente significativo de la vinculación de este emperador con Serapis, los diez tipos monetarios emitidos en Alejandría con la efigie del dios nilótico, sólo o acompañado del emperador (GRIBAUT, 2020:6); por lo que podríamos mantener que esta fue la etapa de máxima difusión de los cultos isíacos (MaLAISE, 1972:437443; VIDMAN, 1970:106-124).

Durante la Anarquía militar (238-265 d.C.) habría que destacar el extenso número de emisiones de Gordiano III (238-244 d.C.) (RIC IV-III=Antioquía 30 v; SNRIS=Alejandría 602c, p. 37) y Filipo il el Joven (247-249 d.C.) (SNRIS=Marcianópolis 28, p. 45). Además, de la aparición del nombre de estos dos últimos en Mesia Inferior (SNRIS=Dionisópolis 5-22, p. 45, 46; Marcianópolis 28-74, p. 45, 46; Odessa 18-48, p.45, 46; Tomis 25-43, p. 45, 46) y Tracia (SNRIS=Mesembria 4-22, p. 45-46). Gordiano III y Filipo II hicieron representar sus bustos en compañía de Serapis, en un intento por mostrar que poseían los mismos poderes que el dios, en un contexto de inestabilidad política (BRICAUlt, 2008:246-247). Además, el filósofo griego Plotino ejerció una gran influencia sobre Gordiano III, ante la veneración a Serapis (MALAISE,1984:445; PÉREZ, 2020:258-267). Las emisiones de Gordiano III estuvieron vinculadas a la victoria sobre su expedición en Tracia y Mesia (CALOMINO, 2013:110).

El final del período anárquico del imperio viene de la mano de Galieno (253268 d.C.), emperador que se caracterizó por la abundancia de monedas que acuñó durante su reinado; síntoma inequívoco de la instrumentalización de la acuñación monetaria como mecanismo de propaganda política. También hay que destacar a Póstumo (260-269 d.C.), quien se acogió a la advocación protectora SERAPIDI CONSERV AVG. Los últimos testimonios de numerario dedicado a Serapis, los

29 No debemos olvidar la potente carga ideológica que subyace tras el Sueño de Vespasiano con Serapis rememorando el pasaje onírico de Ptolomeo Soter (PlutARCo, Is. 28=362 A); una fórmula con la que investir al emperador en el Serapeo de Alejandría a través de una sanción religiosa emanada del dios alejandrino. Este hecho posibilitó la cercanía a lo divino del emperador, como un símbolo con el que perpetuar a la nueva dinastía en el poder. Este vínculo, entre el emperador y Serapis, viene acompañado de todo un programa iconográfico propagandístico, a través de diversas emisiones monetarias. 
encontramos durante el reinado del emperador Maximino Daya César (305-313 d.C.), a principios del siglo IV. Resulta revelador que este emperador haga figurar en el reverso de algunas de sus emisiones el Sol Invictus y en la mano un busto de Serapis. Estas fueron acuñadas también por Licinio (308-325 d.C.) y Constantino (306-337 d.C.) (PÉRez, 2020:249).

La imagen de las monedas está formada por símbolos culturales que permite múltiples lecturas según los responsables de su fabricación, así como los espectadores, usos y espacios donde se ubica (AMANDRY \& BURNETT, 2005:757). Estos productores, así como los receptores, comparten el mismo conocimiento iconográfico que hace que la imagen sea reconocible y porte un significado, aunque el espectador siempre puede darle una nueva interpretación (BRICAULT, 2017:224-225). Sin embargo, no nos hallamos ante la producción canónica de la imagen del dios, llegando a existir más de 74 tipologías monetarias diferentes (VEYMIERS, 2009:211).

La mayoría de las monedas representan al dios solo. Junto a Isis lo hace, como hemos visto, en dos casos: bustos o de pie. Los bustos de Serapis en primer plano e Isis en segundo los hallamos en Alejandría (Svoronos=Alejandría 1124.1; SNRIS= Alejandría 2, 173, 193, 256, 282, p. 42, 43, 48), Catania ${ }^{30}$ (SNRIS=Catania 1,2, p. 42, 43, 181), Tracia (Moushmov=Perinto 4398; SNRIS= Perinto 1,2, pp. 42, 77 y 203) y Asia Menor (SNRIS=Aegae 2a, p. 42; Nicaea 5, 9 p. 42 y Sinope 10, p.42, 103). Respecto a los bustos enfrentados de Isis y Serapis aparecen en los reversos de Bitinia (SNRIS=Nicomedia 7, 18, 20, 21, p. 43, 73); Cilicia ${ }^{31}$ (SNRIS= Aegae $^{32}$ 1, p. 43, 151; Flaviopolis ${ }^{33} 1-3,5,8$, p. 43, 154; Irenopolis $^{34} 1-6$, p. 43; Seleucia ad Calycadnum ${ }^{35} 4-6$, p. 43), Pisidia $^{36}$ (SNRIS= Isinda 1-4, p.43) y Alejandría (SNRIS= $257 b$, p.43). De manera menos común puede aparecer la triada formada por Isis, Serapis y Harpócrates. Este último es representado en una pequeña imagen entre ambos dioses (SNRIS= Nicomedia 18,20, p. 44, 73 y Alejandría 214, p. 44).

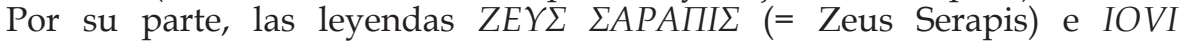
SOSPITATORI (= Júpiter protector), ejemplifican la adaptación que vivió el dios tanto desde la mentalidad griega como romana. Es decir, un dios híbrido, que nació de la fusión de la religión griega y egipcia, terminó, convirtiéndose en una divinidad importante en el Imperio Romano. La expansión de los cultos de origen oriental por Roma supuso un elemento de cohesión ideológica, que se vio atraída por las promesas de salvación con una vida después de la muerte; en este sentido, Serapis, como divinidad salvífica, resuelve el desasosiego generado por la religión romana oficial, sin esperanza de una posterior resurrección (ALVAR, 2001). Al culto de la deidad Serapis se sumaron las clases populares (navegantes, comerciantes, esclavos...); pero, sobre todo, una parte importante de la élite intelectual, de los sectores más privilegiados y de las oligarquías provinciales, quienes impulsaron el culto una vez implantado en Roma. Igualmente, el ejército especialmente en aquellas legiones instaladas en la frontera danubiana y en el oriente romano, dado que algunos emperadores fueron legitimados por sus soldados (Vespasiano,

\footnotetext{
30 Ciudad de la provincia de Catania (Sicilia).

31 En la antigüedad hacía referencia a zona costera meridional de Anatolia, actual Çukurova (Turquía). 32 Ciudad del Peloponeso, actualmente la antigua ciudad está cerca de Akrata (Macedonia).

33 Ciudad de Cilicia, actualmente localizada cerca de Kadirli (Turquía).

34 Ciudad en Cilicia, actual Düziçi (provincia de Osmaniye).

35 Localidad de la provincia de Mersin, actual Silifke (Turquía).

36 Ciudad de la provincia de Pisidia, actual Antioquía de Pisidia (Turquía).
} 
Séptimo Severo, Filipo el Árabe o Constantino I) y vinculados a Serapis, como hemos podido comprobar.

Por otro lado, los diversos emperadores que se vincularon a Serapis hicieron uso de un programa iconográfico monetario del dios alejandrino, destinado a legitimar su poder a través del acercamiento a lo divino, utilizando para ello motivos propagandísticos asociados a la figura del emperador. En este sentido, entran en juego los atributos que portan o acompañan al dios como expresión de una simbología con la que señalar diferentes parcelas de poder. De esta forma, la representación de la divinidad acompañada del águila ${ }^{37}(\mathrm{MILNE}=1370)$ adquiere múltiples connotaciones; así, en su vinculación con los emperadores queda asociada a la victoria, la autoridad y el poder militar, sin llegar a perder como pájaro divino su valor cósmico o celestial (VeYMIERS, 2003:277-278) cualidades que transmite al dios alejandrino convirtiéndolo en el soberano del Cosmos y al emperador del Imperio ${ }^{38}$. El águila puede aparecer, además, posada sobre un altar localizado tras Serapis a caballo ${ }^{39}$; una imagen que a través del equino otorga a la divinidad y por ende al emperador, una capacidad extraordinaria como protector invencible que lucha contra las fuerzas hostiles (VeYMIERS, 2009:56 182).

Otro objeto que acompaña al dios alejandrino en su identificación con HeliosSol es el préstamo iconográfico de la corona radiada, vinculada con su carácter cósmico en el contexto de un mismo marco cultural romano. La corona concede, tanto a los emperadores que se hacen representar con ella como a Serapis, la competencia de adquirir cualidades solares. El uso de este tipo de corona se convirtió en el siglo III d.C. en un símbolo de exaltación de poder universal imperial (Pérez, 2020:134), asociado a la figura del Sol Invictus, en un momento en el que se inscribe una tendencia hacia el henoteísmo y cuya consecuencia inmediata para nuestra divinidad alejandrina, sería la concepción de Serapis como una divinidad panthea.

Finalmente, una singular representación a la que hemos aludido durante la Tetrarquía se refiere a aquella en la que Sol aparece en el reverso de las monedas imperiales sujetando en su mano la cabeza de Serapis. Esta imagen transmite un nuevo mensaje propagandístico en la zona Oriental del Imperio; pues este tipo figurativo podría interpretarse como una expresión de soberanía de la divinidad dentro del cosmos, en la que Sol convierte a Serapis en kosmocrator, en un acto de plena interacción entre ambas divinidades. Debemos tener en cuenta que los tres emperadores que emiten esta representación en Oriente, Maximino Daya, Licinio y Constantino (HUBEÑÁK, 2019: 655-669) tienden, en términos generales, a implantar un ideario religioso tradicional de carácter sincrético, asociado al trasfondo de la victoria imperial y el origen divino del poder; bien sea con Hércules o con divinidades de origen oriental, como Serapis o Apolo, respectivamente; será el carácter Invictus de estos dioses, el que les lleve a la aceptación de un sincretismo religioso de naturaleza solar, protagonizado por la figura de un Sol Invictus en

$37 \mathrm{El}$ águila no es un atributo que acompaña exclusivamente a Serapis; de hecho, es un símbolo inequívoco de Zeus/Júpiter, además de que aparece con otras divinidades de origen oriental como Júpiter Dolichenus, Júpiter Heliopolitano, Sabacios, Cibeles, e incluso, Isis.

38 Los emperadores que aparecen con este tipo de representación fueron los Antoninos, Adriano, Antonino Pio, Lucio Vero y Marco Aurelio; los Severos, Geta, Caracalla y Alejandro Severo; finalmente, de la Anarquía militar, Gordiano III; véase VeYMIERs (2003: 268-269).

39 Como hemos expuesto más arriba, estas figuraciones van desde el reinado de Cómodo hasta Gordiano III. 
acción recíproca con Serapis, tal y como aparece expresado en dicha imagen.

En definitiva, no existió una imagen preceptiva del dios nilótico a través de la numismática, por lo tanto, se muestra heterogénea, a la vez que evolutiva a lo largo del imperio. El interés de Serapis por algunos emperadores aparece como una opción religiosa en la medida en la que divinidad alejandrina les legitima, les protege y les conduce hacia la victoria; lo que nos indicaría, en última instancia, que la imagen de la divinidad fue utilizada según las necesidades de los emperadores conforme a los diversos contextos políticos e ideológicos.

\section{FUENTES CLÁSICAS}

Cayo suetonio tranluilo, Vida de Tiberio, Biblioteca Básica Gredos, Madrid [trad. R. Ma Agudo Cubas, 2010].

Diodoro de Sicilia, Biblioteca Histórica, Vol. I, Biblioteca Clásica Gredos, Madrid [trad. F. Parreu Alasá, 2001].Flavio Josefo (1997): Antigüedades Judias, 2 vol., 45, Ediciones AKAL, Madrid [trad. José Vara Donado, 1997].

Elío Arístides; Luciano de Samosata (1989): Discursos sagrados: Sobre la muerte del peregrino. Alejandro o el falso profeta, vol. 25, Ediciones AKAL, Madrid [ed. M. Giner Soria].

Heródoto de Halicarnaso, Los nueve libros de la Historia, Libros I-II, Biblioteca Clásica Gredos, Madrid [trad. C. Shrader, 1992].

Macrobio Ambrosio Aurelio Teodosio, Saturnales, Tres Cantos, Akal, Madrid [trad. Juan Francisco Mesa Sanz, 2009].

Plutarco de Queronea, Obras morales y de costumbres, vol. 6, Biblioteca Clásica Gredos, Madrid [trad. F. Pordomingo Pardo y J. A. Fernández Delgado, 1995].

Tertuliano, Apologético, A los gentiles, Biblioteca Clásica Gredos, Madrid [trad. revisada por Eustaquio Sánchez Salor, 2001].

VAlerio Máximo, Hechos y dichos memorables, Biblioteca Clásica Gredos, Madrid [trad. Santiago López Moreda, Ma Luisa Harto Trujillo y Joaquín Villalba Álvarez].

\section{WEBGRAFÍA}

American Numismatic Society, http:/ / numismatics.org [Consultada: 05/10/21].

Ancient Coins: Roman, Greek, Byzantine and Celtic Numismatics, https://www.wildwinds.com/coins/ [Consultada: 04/10/21].

\section{REFERENCIAS}

AlFöLd, A. (1937) : A Festival of Isis in Rome under the Christian Emperors of the IV $V^{\text {th }}$ century, Institute of Numismatics and Archeology of the Pázmány-University, Budapest.

Alvar, J. (2001): Los misterios: Religiones «orientales» en el Imperio Romano, Crítica, Barcelona.

AlföDI, A. (1965-1966): «Die alexandrinischen Göter und die Vota Publica am 
Jahresbeginn », JAC, 8-9: 53-87.

Amandy, M. \& BurnetT, A. (2015): Roman Provincial Coinage, Nerva, Trajan and Hadrian (AD 96-138), v. III, The British Museum \& Bibliothèque Nationale de France.

Arroyo del fuente, M. A. (1999): «Isis y Serapis, legitimadores de la realeza en época Ptolemaica», Boletín de la Asociación Española de Egiptología, 9: 157-174.

BackHoum, S. (1999): Dieux égyptiens à Alexandria sous les Antonins. Recherches numismatiques et historiques, CNRS Editions, Paris.

BAbelon, J. (1951): «Le camée d'Octavie», Monuments et mémoires de la Fondation Eugène Piot, 45, Académie des Inscriptions et Belles-Lettres, Liens, 77-87.

BeAujeu, J. (1955): La Religion romaine à l'apogée de l'Empire. I, La Politique religieuse des Antonins, 96-192, Paris.

BRICAULT, L. (1998): «Sarapis dans l'empiere kouchan», Bulletin de la Société française de numismatique, 10: 249-254.

Bricault, L. (2001): Atlas de la diffusion des cultes isiaques: (Ive S. Av-IVe S. APR. J.C.), préface de Jean Leclant, Diffusion de Boccard, Paris.

Bricault, L. (2006): Isis, Dame des flots, Ægyptiaca Leodiensia, 7, Liège.

BRICAUlt, L. (2008): Sylloge Nummorum Religionis Isiacae et Sarapicae, con la colaboración de Ashton, R.; Delrieux, F., Leschhorn, W. [et al.]; prefacio de Leclant, J. Mémoires de l'Académie des inscriptions et Belles-Lettres, XxXVIII, Boccard, Paris.

BRICAUlt, L. (2013): Les cultes isiaques dans le monde Gréco-Romain: Documents réunis, traduits et commentés par Laurent Bricault, Les Belles Lettres, Paris.

BRICAULT, L. (2014): SNRIS Sumpplément I. Bibliotheca Isiaca, vol. III, bajo la dirección de L. Bricault, L. y R. Veymiers, Bordeux Ausonius Éditions, Paris, 245-284.

BRICAULT, L. (2017): «Sarapis au droit des monnaies provinciales romaines d'Asie Mineure et de Thrace», The Numismatic Chronicle, 177: 213-244.

Bricault, L.; Ashton, R. (2008): Sylloge Nummorum Religionis Isiacae et Sarapiacae (=SNRIS), Belles Lettres, Paris.

BOHEE, Y. (2000): «Isis, Sérapis et lármee romine sous, le haut-empire», en L. BRICAUlt (ed.), De Memphis à Rome, RGRW 140, Brill, Leiden-Boston Köln, 129-148.

Burel, J. (1911): Isis y les Isiaques sous l'Empire romain, Bloud, Paris.

Burnett, A.; Amandry, M.; Ripollés, P.P. (1992): Roman Provincial Coinage, I, London-Paris.

Carradice, I.A. (2012): «Flavian Coinage», en W.E. Metcalf (ed.), The Oxford Handbook of Greek and Roman Coinage (The Oxford Handbooks), Oxford-New York-Auckland, 375-389.

Colomino, D. (2013): «Die-sharing in Moesia Inferior under Gordian III», The Numismatic Chronicle, 173, 105-126.

Cumont, F. (1 $1^{\mathrm{a}}$ Ed. Paris 1906; Ed. española 1987): Las religiones orientales y el paganismo romano, Akal Universitaria, Madrid.

DattARI-SAvio, A. (2007) : Catalogo della collezione Dattari, Giulio Brenarde Editore, Trieste.

Delrieux, F. (2013): «Roma dans le panthéon monétaire carien sous les premiers Sévères: un nouveau témoignage sur les bronzes de Stratonicée», Revue Numismatique, 6(170), 61-100, Lyon.

DunAND, F. (1968) : «Les deliaca de l’Histoire Auguste», BFS, 47 : 151-155.

DunAND, F. (1980): «Cultes egyptiens hors d’Egypte. Essai D’analyse des conditions 
de leur diffusion», Religions, pouvoir rapports sociaux, 32 : 71-148.

García Aguado, P. (2001): «El culto a Isis grecorromana en la Dinastía Severa al inicio del siglo III d.C.», Boletín de la Asociación Española de Egiptología, 11: 171-182.

Gasparini, V. (2009): «I culti egizi», en F. CoArelli (ed.), Divus Vespasianus. Il bimillenario dei Flavi. Catalogo della mostra (Roma, 27 marzo 2009-10 gennaio 2010), Milano, 348-353.

Gribaut, J. (2020): «La représentation de Sarapis sur les monnaies d'Alexandrie sous le principat de Caracalla», en D. Moreau (ed.), Master 2018: HistoireArchéologie-Histoire de l'art, Lille, Presses universitaires du Septentrion, France.

HubeÑÁK, F. (2019): «La tetrarquía y su teología política: sus implicaciones en las relaciones iglesia-imperio», REDC, 76: 649-684.

JoHnston, A. (1983): "Caracalla's Path: The Numismatic Evidence», Historia: Zeitschrift Für Alte Geschichte, JSTOR, 32: 58-76.

Johnston, A. (2020): «À propos de deux monnaies émises à Rome à l'effigie du jeune Caracalla Auguste», Laïus, La Revue étudiante en Histoire et en Lettres de L'uqar, 13: 51-68.

KRILL, M.R. (1978): «Roman paganism under the Antonines and Severans», ANRW, vol. 2, Berlin-New York.

Le Coursu, F. (1977): Isis. Mythe et mystéres, Les Belles lettres, Paris.

López Salvá, M. (1992): «Isis y Sarapis. Difusión de su culto en el mundo grecorromano», Minerva: Revista de filología clásica, 6: 161-192.

Malaise, M. (1972): Les conditions de pénetration et de diffusion des cultes égyptiens en Italie, EPRO 23, E.J. Brill, Leiden.

Malaise, M. (1975): «Problèmes soulevés par l'iconographie de Sarapis», Société d'Études Latines de Bruxelles-Latomus, 34: 383-391.

Malaise, M. (1984): «La diffusion des cultes égyptiens dans les provinces européenes de 1’Empire romain», ANRW II 17.3, New York, 1615-1691.

Martín Atajo, A. (1994): "En torno a la incubatio», Sexo, muerte y religión en el Mundo Clásico, ARYS, Ediciones Clásicas, Madrid, 135-144.

Mattingly, H. ; Sydenham, E.A. (1936): Roman Imperial Coinage, IV, I, London.

Mattingly, H.; Sutherland, C.H.V. (1949): Roman Imperial Coinage, IV, III, London.

Moushmov, N. (1912): Ancient Coins of the Balkan Peninsula and the Coins of the Bulgarian. Sofia.

MiLne, J.G. (1972): Catalogue of Alexandrian Coins, Oxford.

Montero, S. (2006): "Harúspices contra isiaci. La oposición aruspicial a la introducción del culto isíaco en Roma», en J.A. Delgado (ed.) Dioses viejosdioses nuevos formas de incorporación de nuevos cultos en la ciudad antigua, Fundación Canaria Mapfre Guanarteme, La Laguna, 41-52.

Pérez Yarza, L. (2020): El culto a Sol en occidente del Imperio Romano, Tesis doctoral inédita, Universidad de Zaragoza.

ReGGiani, A.M. (2006): «Adriano y Egipto», Romula, 5: 85-112.

SANZI, E. (2008): «Religiosidad popular cristiana, magia y cultos orientales en los primeros siglos de nuestra era: ejemplificaciones histórico-religiosas», Badue: Revista de la Sociedad Española de Ciencias de las Religiones, 2: 57-73.

SFAmENI, G. (2000): «Les cultes isiaques en Sicile», en L. Bricault (ed.), De Memphis à Rome, RGRW140, Brill, Leiden-Boston-Koln, 35-62.

SEAR, D. (2000): Roman coins and their values: The Republic and the Twelve Caesars (280 
a.C.- 96 d.C.), I, London.

Sierra, R.; CAMPOS, I. (2010): «Actuación de los magistrados en la introducción de cultos orientales en la Roma Antigua», en E. SuÁrez DE LA TORRE y E. Pérez Benito (eds.), Lex Sacra: Religión y Derecho a lo largo de la Historia, Trotta, Madrid, 55-66.

SIERRA, R. (2006): «Mujer y Misterios: isíacas ¿hechizo de amor divino o sumisión?», en R.M. Sierra Del Molino, Mujeres en Movimiento. Historia y Literatura, Instituto Canario de la mujer y ULPGC, Las Palmas de Gran Canaria, 57-69.

SILVER, M. (2012): «The plague under Commodus as an unintended consequence of Roman grain market regulation», Class World, 105 2): 199-225.

Svorono, J. (1890): Numismatique de la Crète Ancienne : accompagnée de l'histoire, la géographie et la mythologie de l'île, Protat Frères Imprimeurs, Mâcon.

Stambaugh, J.E. (1972): Serapis under the early Ptolomeis, EPRO 25, Brill, Leiden.

TERMIS, O. (2020): «Etnicidad y emulación: estudio y desarrollo de la iconografía de la divinidad greco-egipcia Serapis», Espacio Tiempo y Forma, Serie II, Historia Antigua, 33: 13-34.

TRAPERO, R. (2017): «La celebración de los votos imperiales y su reflejo en las emisiones romanas de los siglos i y II d.C.», en J. DE SANTIAgo Fernández y J.Ma DE Francisco Olmos (eds.), Homenaje a María Ruiz Trapero, Universidad Complutense de Madrid, Madrid: 149-186.

Turcan, R. (1983): Numismatique romaine du culte métroaque, EPRO, 97, Leiden.

Turcan, R. (2001): Los cultos orientales en el mundo romano, Colección Historia Biblioteca Nueva, Madrid.

VAGI, D. (1999): Coinage and History of the Roman Empire, I-II, Routledge, London.

Varbanov, I. (2007): Greek Imperial Coins And Their Values, III: Thrace (from Perinthus to Trajanopolis), Chersonesos Thraciae, Insula Thraciae, Macedonia, Bourgas.

VeYmiers, R. (2003): «Sérapis et l'aigle: polysémie d'un iconotype», XLI Session des journées des orientalistes Belges, Bruxelles, 265-285.

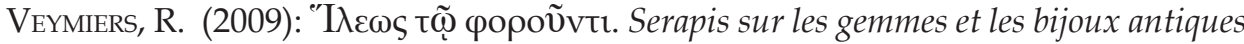
(Mémoires de la Classe des Lettres. Collection in $-4^{\circ}-3 e$ série I.2061; Bruxelles).

VeYMiERS, R.; BRICAULT, L. (2018): «L'Iseum Campense comme type monétaire», Temple-monument-Lieu de mémorie, The Iseum Campense from the Roman Empire to the Modern Age: Historical, archaelogical and historiographical perspectives, Royal Netherlands Institute in Rome, Rome, 127-155.

VIDMAN, L. (1970): «Isis und Sarapis bei den Griechen und Romern (Epigraphische Studie zur Verbreitung und zu den Trägern des ägyptuschen kultes)», De Gruyter, Berlin.

WelLes, C.B. (1962): «The discovery of Sarapis and the foundation of Alexandria», Historia: Zeitschrift für Alte Geschichte, 11 (3): 271-298.

WitT, R.E. (1971): Isis in the Greco Roman World, Cornell University Press, London. 